\title{
KATI ATIK TOPLAMA AMAÇLI BİR AKILLI SISTEMINN TASARIMI VE UYGULAMASI
}

\author{
Kadir ÇAVDAR ${ }^{11}$, Murat KÖROĞLU ${ }^{2}$, Bülent AKYILDIZ ${ }^{2}$, Mustafa AKYILDIZ $^{2}$ \\ ${ }^{1}$ Uludă Üniversitesi, Mühendislik Fakültesi, Makine Mühendisliği Bölümü, 16059, Bursa \\ ${ }^{2}$ AKA Otomotiv San. ve Tic. A.Ş. Örnekköy Yolu, Orhangazi, Bursa
}

\begin{abstract}
ÖZET
Katı atık toplama sistemleri günümüz toplumsal yapısı ve şehirleşmede çok önemlidir. Oldukça yüksek maliyetler ödenerek ortaya konmuş olsalar da şehirlerde çalışan sistemlerin yeterli verimlilikte ve kalitede hizmet vermedikleri açıktır.

Bu çalışmada; şehirlerde yüksek verimlilik ve düşük maliyetlerle (\%50-80 daha az maliyetlerle) çalışabilecek yeni bir akıllı katı atık toplama sisteminin tasarım yaklaşımı, fizibilite etüdü ve yapılan uygulama ile kazanılan tecrübeler açıklanmaktadır.
\end{abstract}

Anahtar Kelimeler: Katı atık, toplama sistemi, sistem tasarımı, optimizasyon, verimlilik

\section{DESIGN AND IMPLEMENTATION OF A SMART SYSTEM AIMING TO COLLECT SOLID WASTE}

\begin{abstract}
Solid waste collection systems are very important in today's social structure and urbanisation. Despite quite high costs are paid for them, it is clear that the waste collection systems presented in the cities does not offer a service with the sufficient efficiency and quality.

This study explains the design approach, feasibility survey and the experiences acquired by means of the application conducted with regard to new smart solid waste collection system which can applicable with high efficiency and low cost (50\% to $80 \%)$.
\end{abstract}

Keywords: Solid waste, collection system, system design, optimization, efficiency

\section{GíRiş}

Uygarlığın gelişmesi ile birlikte insanlar refah seviyesinin en üstlerinde olabilmek için şehirlerde yaşamaya başlamışlardır. Şehirleşme oranı günümüzde ülkelerin gelişmişlik seviyesi göstergelerinden bir tanesidir. Ancak şehirleşme ile birlikte çok sayıda bireyin bir arada yaşaması; trafik, sağlık ve güvenlik gibi bazı alanlarda problemleri de beraberinde getirmiştir. Bu problemlerin en önde gelenlerinden olan katı atık toplama sistemlerinin kurulup çalıştırılması şehirlerde önemli organizasyonların yapılmasını gerektirmektedir. Ancak günümüz şehirleri incelendiğinde, katı atık toplamanın genellikle ya kötü şekilde yapıldığı veya sistem çalışma veriminin çok düşük olduğu sonucuna ulaşmak sürpriz olmaz. Şehirlerde yaşayan bireylerin şikâyetleri ve aynı zamanda da şehri yöneten otoritenin katı atık toplama maliyetleri konusundaki memnuniyetsizlikleri

\footnotetext{
${ }^{1}$ Corresponding author. Tel. +90 224294 19 75; Fax: +90 224294 19 75; e-mail: cavdar@uludag.edu.tr
} 
gözlendiğinden bu alanda iyileştirme amacı ile bu çalışmada tanıtılacak olan yeni bir çöp toplama yaklaşımı ortaya konulmuştur. Akıllı Çöp Toplama Sistemi olarak isimlendirilen bu platformun çalışması ve uygulamanın sonuçları yayının takip eden bölümlerinde sunulacaktır.

Katı atık toplama sistemleri konusunda bilimsel literatürde çok fazla çalışma mevcut değildir. Az sayıda bulunan çalışmalar bu bölümde özetlenecektir.

Vicentini ve diğ. [1] tarafından yapılan yayında, içerisinde atık seviye algılama algılayıcılarının yer aldığı çöp konteynırlarının kullanıldığı bir çöp toplama sisteminin yapısı kurgulanmışıı. Çin'in Şangay kentinde test edilen sistemde kullanılmış olan konteynırlardaki algılayıcıların yerleşimleri Şekil 1'de görülmektedir.

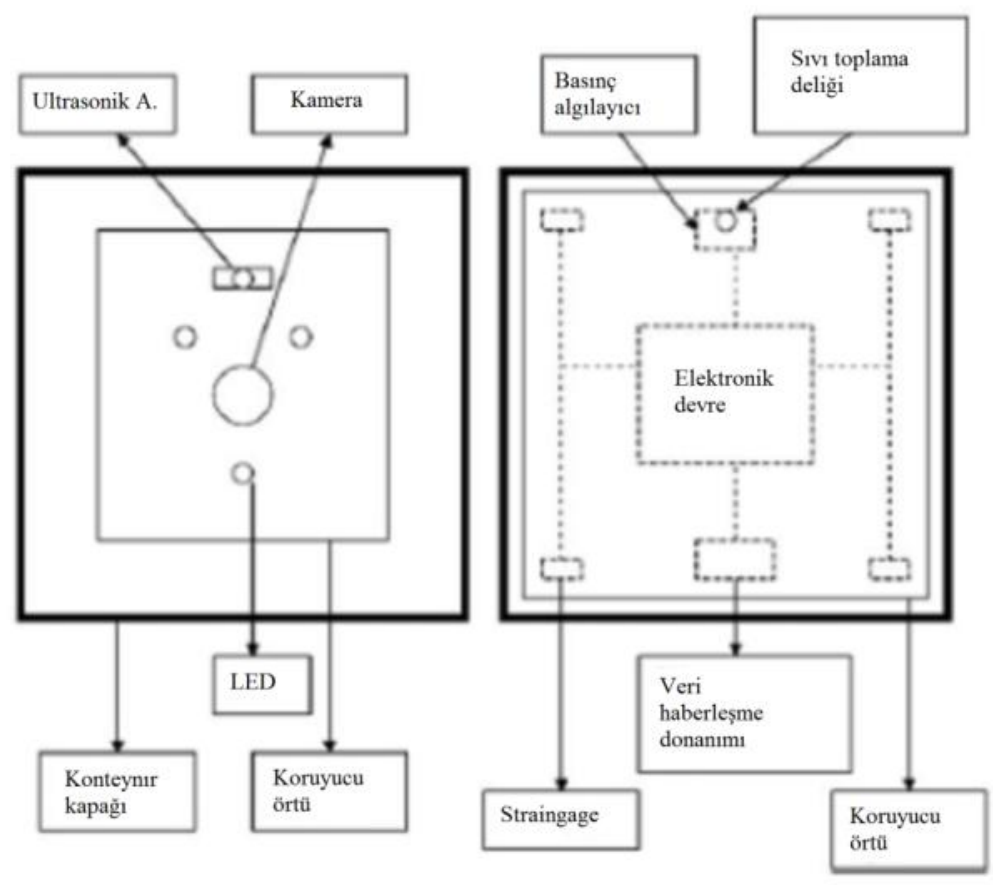

Şekil 1. Konteynırlar içerisindeki algılayıcı yerleşimleri [1]

Bonomo ve diğ. [2] ise Buenos Aires örneğinde, matematiksel programlama tekniği ile çöp toplama olayını optimize etmişlerdir. Klasik en kısa yol algoritmasının kullanıldığ çalışma ile şehrin küçük bir bölgesinde sağlanabilecek yıllık tasarruf 200000 dolar olarak hesaplanmıştır.

Çöp toplamada en kısa yolun hesabında çeşitli yaklaşımların kullanıldığı görülmektedir. Ismail ve Loh [3] da çalışmalarında optimizasyon işlemini karınca kolonisi yaklaşımı ile yapmışlardır. 12-48 nokta arasındaki transferler için yapılmış olan teorik çalışmanın çöp toplama problemlerine uygulanabilirliği yayında tartışılmıştır. Benzer bir teori Karadimas ve diğ. [4] tarafından da çöp toplama rotasının optimizasyonu için önerilmiştir.

Johansson [5], İsveç'te 3300 algılayıcı ve kablosuz haberleşme ekipmanları ile donatılmış konteynırlı bir sistemde katı atık toplama olayının optimizasyonu çalışmasını sunmuştur. Toplama işleminde optimal rotanın kararının verilmesi için konteynırlardan gelen gerçek zamanlı datalar kullanılmaktadır. Çalışma sonucunda katı atık toplama maliyetinin \%10-20 arasında düştüğü tespit edilmiştir.

Faccio ve diğ. [6] ise çalışmalarında gerçek zamanlı verileri kullanan çok amaçlı modellerini çöp toplama işlemine uygulamışlardır. Çalışma yaklaşık 100000 nüfuslu bir İtalya kentine uygulanmış olup projede kullanılan yaklaşım Şekil 2'de görülmektedir.

Optimum rotanın tespitinde genetik algoritmanın kullanıldığı bir çalışma Viotti ve diğ. [7] tarafından sunulmuştur. Önerilen algoritmanın bir yazılıma uygulandığında verimliliğin yükseltilebileceği savunulmaktadır. Nuortio ve diğ. [8] çalışmalarında, Batı Finlandiya uygulamasında çöp toplama olayının optimizasyonu için geliştirdikleri sistemi tanıtmaktadırlar. Çalışılan bölgede farklı çöp tipleri için farklı boyutta yaklaşık 30000 adet çöp kutusu vardır. Yayında sistemin konsept modeli tanıtılmışıtır. 


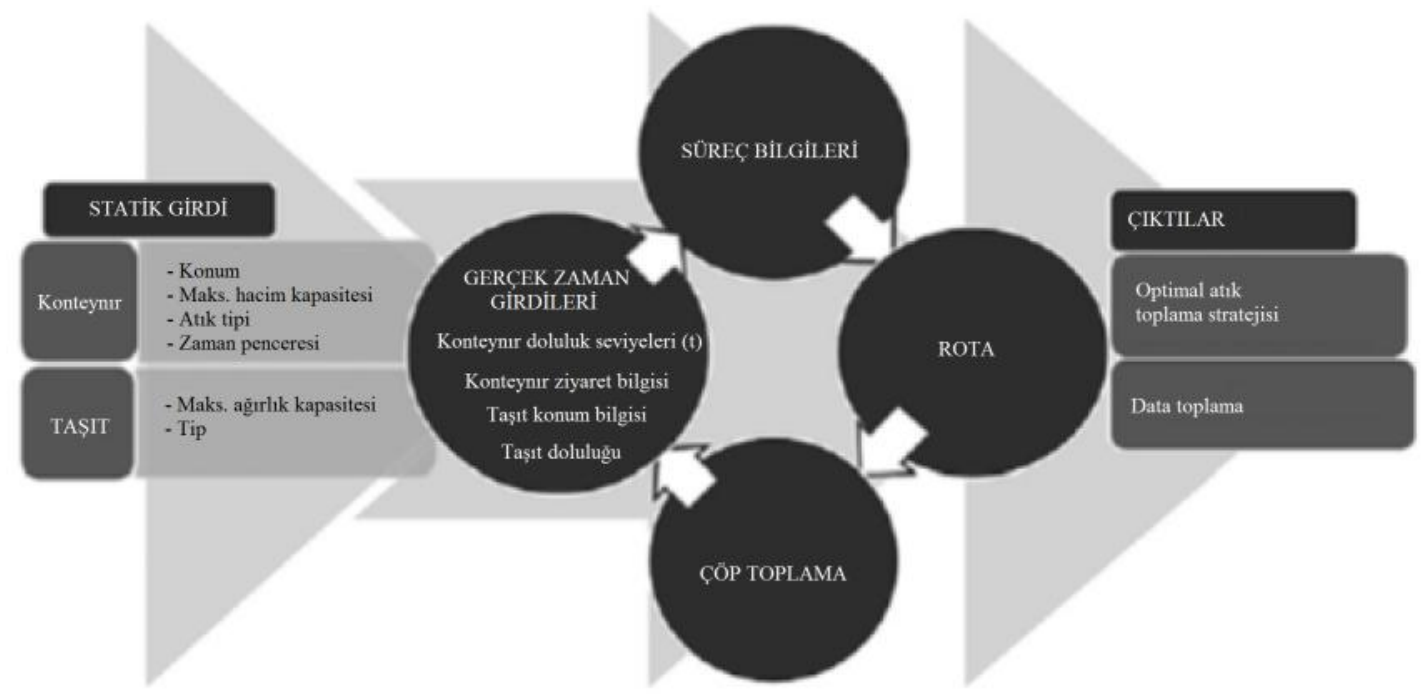

Şekil 2. Katı atık toplama için gerçek zamanda izlenebilir rota planlama modeli [6]

Arebey ve diğ. [9] çalışmalarında RFID (Radyo Frekansı ile Tanımlama-Radio-Frequency Identification), GPS (Küresel Konumlama Sistemi-Global Positioning System) ve kameralı sistemler içeren çöp toplama sisteminin tasarım modelini sunmaktadırlar. Sistemde ayrıca konteynır doluluk durumunun anlaşılması için sayısal görüntü işleme tekniği (Digital Image Processing) kullanılmıştır.

Kop [10] tarafından hazırlanan yüksek lisans tez çalışmasında Türkiye'de mevcut olan atık yönetimi mevzuatı ve süreci, bu sürecin dünyadaki örnekleri ve Türkiye'nin bu konuda dünyadaki konumu incelenmiştir. Katı atık toplama süreçlerinin bir aşaması olan çöp toplama sistemlerinin karşılaştırılması ve seçimi için mevcut ve benimsenmesi öngörülen toplama sistemleri hakkında çeşitli özel şirketler, belediyeler, çevre ve orman bakanlığı gibi kamu kuruluşlarından veri toplanarak, bu veriler 1şığında günümüz için en uygun çöp toplama sistemi seçilmiştir.

İstanbul için yapılan bir projeksiyona göre 2010 yılı rakamları ile yıllık 80 Milyon Dolar, Türkiye genelinde de 400 Milyon Dolarlık bir tasarrufun çöp toplama sistemlerindeki revizyon ve verimlilik artışı ile sağlanabileceği hesaplanmıştır [11].

\section{TASARLANAN KATI ATIK TOPLAMA SISTEMI}

Literatür araştırması sonrasında detaylı saha incelemeleri ve konu paydaşları ile yapılan görüşmelerin ardından mevcut sistemlerden daha verimli çalışabilecek yeni bir katı atık toplama sisteminin ortaya konabileceği kanaatine varılmıştır. Bu sistem için, tasarım sürecinin başlangıcında aşağıdaki kriterler ortaya konmuştur:

- $\quad$ Tek merkezden (web portalından) konteynır doluluk oranları takip edilebilecektir,

- $\quad$ Sistemden günlük, haftalık iş planlama raporları alınabilecektir,

- Özel kurgulanmış olan algoritma kullanılarak, GSM/GPRS yardımıyla optimum yol güzergahı belirlenecek, böylece yakıt ve zamandan tasarruf sağlanacaktır,

- İhtiyaca uygun istatistiki raporlama imkanları olacaktır; örneğin bölgelere göre aylık çöp miktarı vb.,

- $\quad$ Klasik 8 adet 400 litrelik konteynır yerine 1 adet yeraltı çöp konteynırı kullanılacaktır,

- $\quad$ Klasik 4 adet çöp toplama aracı yerine 1adet akıllı çöp toplama aracı yeterli olacaktır,

- Sistemdeki toplama araçlarının sayısı azalınca yakıt, tamir, bakım ve zaman tasarrufu da sağlanacaktır,

- Klasik sistemdeki araç arkasında çalışan iki operatör bu sistemde olmayacaktır,

- İşçi sağlığı ve iş güvenliği kurallarına tam olarak uygun bir sistem ortaya konacaktır,

- Şehirlere şehir mobilyası görünümüne uygun modern bir sistem kazandırılacaktır,

- $\quad$ Sistemin ekonomik ömrü iki yıldan on yıla çıkarılacaktır,

- Temizlik işlerine daha ekonomik bir yapı, ergonomi ve hız kazandırılacaktır,

- Trafik akışının engellenmemesi sağlanacaktır,

- $\quad$ Kentlerde gürültü ve görüntü kirliliği ortadan kalkacaktır. 


\subsection{Bir Yerleşim Alanının Katı Atık Toplama Açısından Analizi}

Analiz amacı ile Bursa iline bağlı bir ilçenin (Kestel) altı mahalleden oluşan bir bölgesi seçilmiştir. Bu bölgede günlük yaklaşık 70-75 ton çöp toplanmaktadır. Seçilen altı mahallede toplanan çöp miktarı, analiz edilen yerleşim bölgesinin toplam çöp miktarının \%80'ini oluşturmaktadır. Toplama alanındaki yolların yetersiz olması, konteynırların kapasitelerinin yetersiz olması ve bireylerin çöp çıkarma zamanlarına uymamalarından dolayı çöp kamyonları birçok cadde ve sokağa plansız şekilde defalarca girmek zorunda kalmaktadır. Bu plansızlıklar; gürültü, koku ve emisyon gibi çevresel problemlere neden olmaktadır.

Seçilen yerleşim bölgesi için yapılan örnek fizibilite etüdü Şekil 3'te görülmektedir. Klasik çöp toplama sistemi kullanıldığında bu ilçede personel harcaması için yıllık 647964 TL ödenirken akıllı çöp toplama sisteminde hem personel hem de araç sayısının azalması ile 45576 TL ödenecektir. Akaryakıt ve amortisman giderleri düşünüldügüünde ise yıllık 10537200 TL'lik harcama 629280 TL'ye düşürülebilmektedir. Ayrıca akıllı çöp toplama sistemine dönüştürülmüş olan çöp konteynırları ile de 238750 TL daha tasarruf yapmak mümkündür.

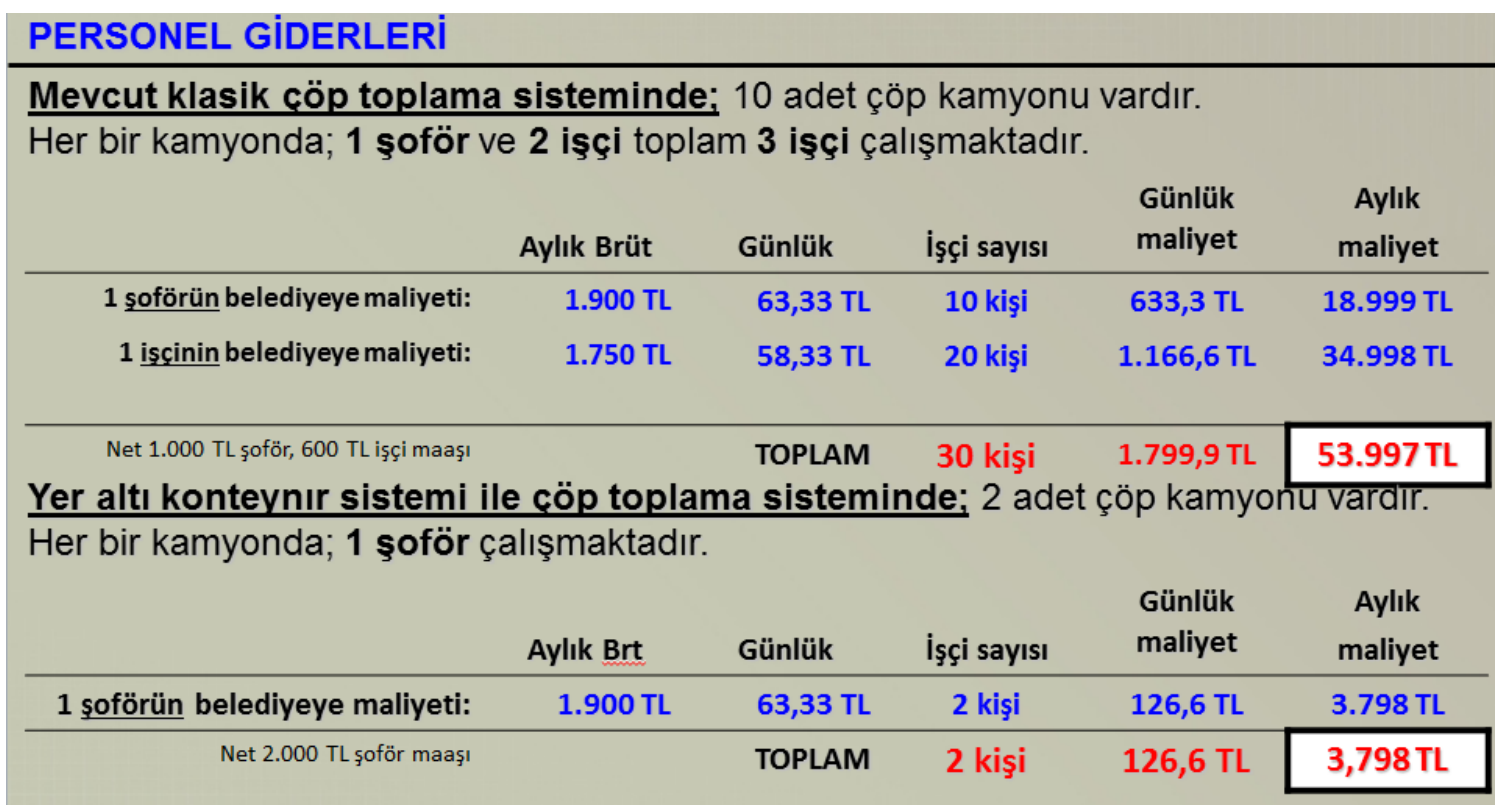

Şekil 3. Küçük bir ilçe için yapılan fizibilite etüdü örneği

\section{AKILLI ÇÖP TOPLAMA SİSTEMI ÇALIŞMA PRENSİi்}

Bursa ilinin Kestel ilçesine kurulumu tamamlanan akıllı çöp toplama sisteminin prensip şeması Şekil 4'te verilmiştir. Sistem üç ana gruptan oluşmaktadır:

1. Konteynırlar (Yeraltı konteynırı, yerüstü konteynırı)

2. Araç (Robotik çöp toplama araci)

3. Portal (Kullanıcı ara yüzüne ulaşmak için oluşturulan başlangıç noktası)

\subsection{Konteynirlar}

Yeraltı konteynırı ve yerüstü konteynırı olmak üzere iki gruptan oluşmaktadır. Yeraltı konteynırı $3,5 \mathrm{~m}^{3}$ ve $5 \mathrm{~m}^{3}$ kapasitelerde üretilmektedir. Konteynırlar yaklaşık 30 adet farklı standart malzemeden ve yaklaşık 200 adet farklı bileşenden oluşmaktadır. $3,5 \mathrm{~m}^{3}$ ve $5 \mathrm{~m}^{3}$ hacimli konteynırlar sırasıyla $750 \mathrm{~kg} 980 \mathrm{~kg}$ 'dır. Yerüstü konteynırları 3,4 $\mathrm{m}^{3}$ kapasitede üretilmektedir. Yaklaşı 20 adet farklı standart malzemeden ve yaklaşı 150 adet farklı bileşenden oluşmaktadır. Yerüstü konteynırının yaklaşık ağırlığı 450 kg'dır ( Şekil 5). 


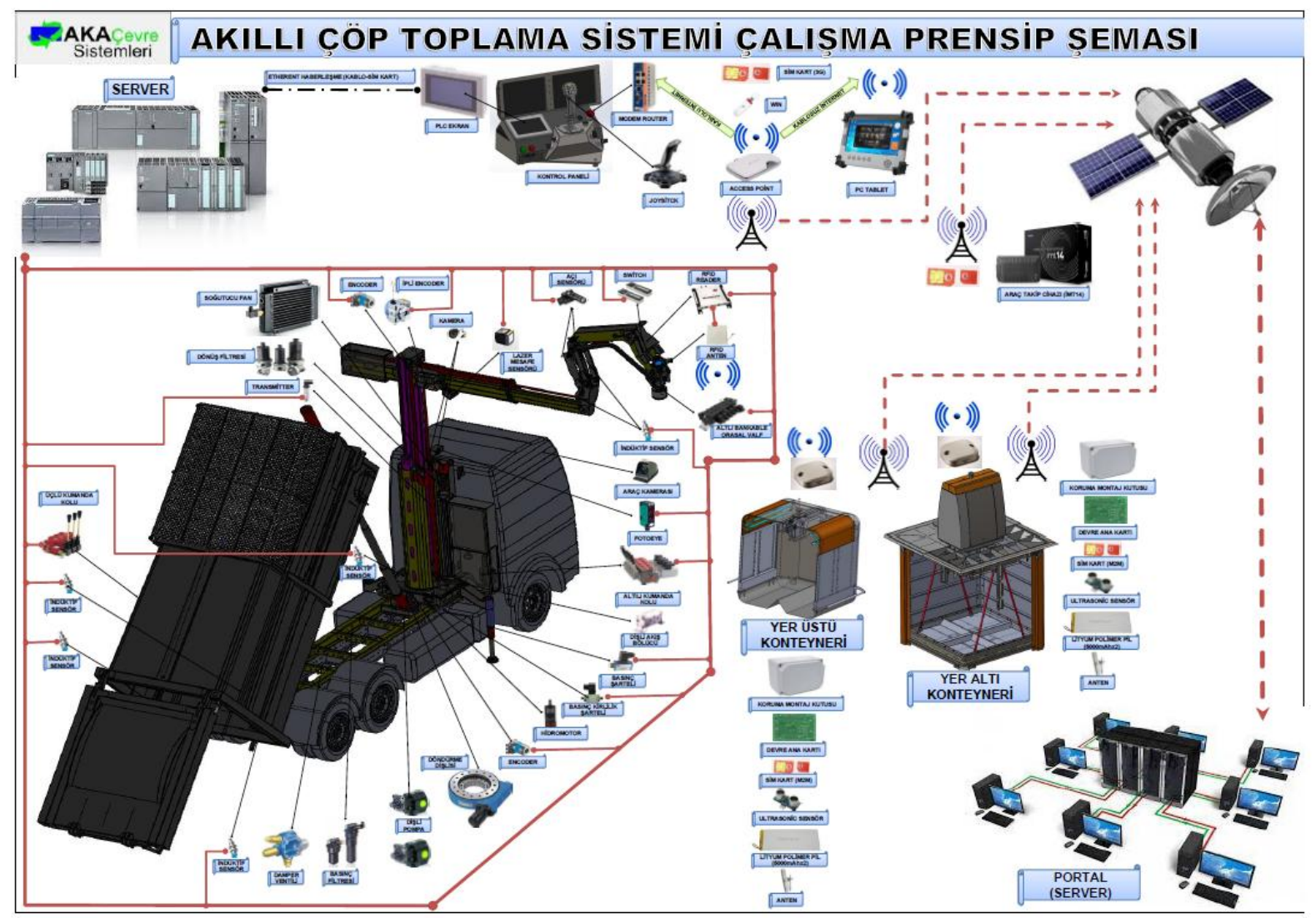

Şekil 4. Akıllı çöp toplama sistemi prensip şeması

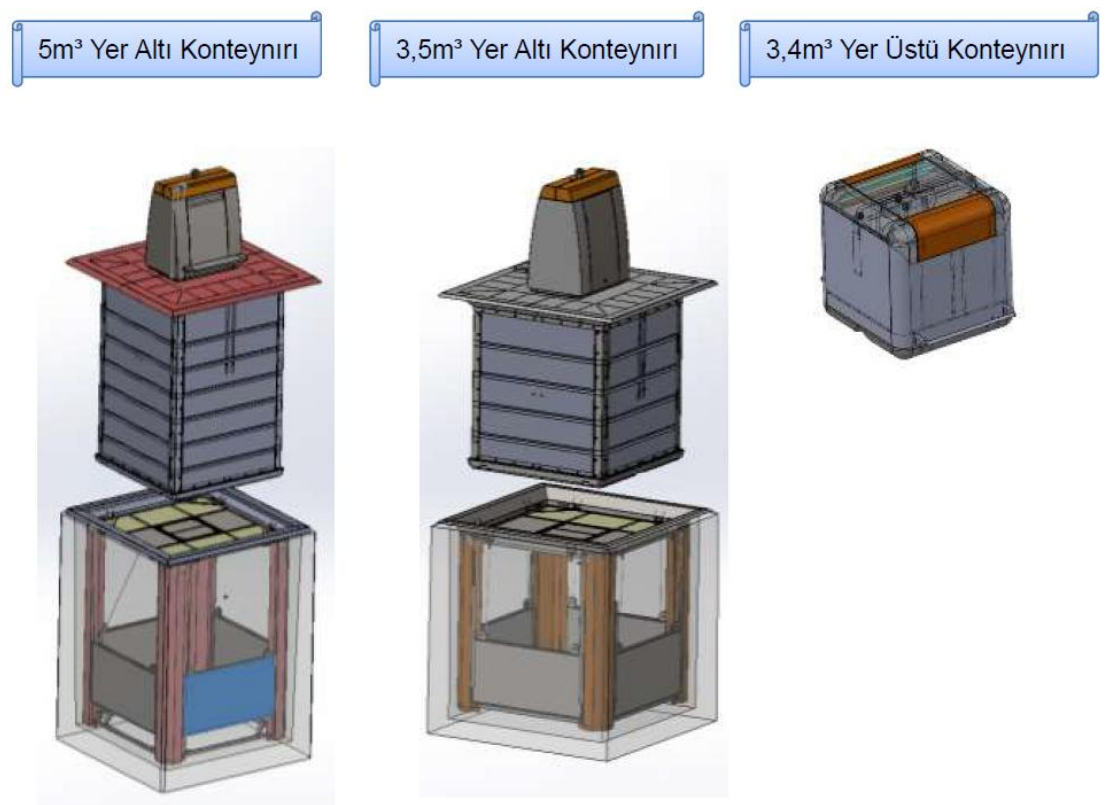

Şekil 5. Sistemdeki konteynır tipleri 
Konteynır içerisine yerleştirilen haberleşme sistemi (Şekil 6); ultrasonik algılayıcı, SIM kart (M2M), iki adet lityum polimer pil (5000 mAh), devre ana kart1, anten ve sistem montaj koruma kutusundan (IP67) meydana gelmektedir. Haberleşme sisteminin işleyiş biçiminde, konteynırda biriken çöplerin miktarı ultrasonik algılayıcı (a) ile ölçülür. Ölçülen değer özel tasarlanmış devre ana kartına (b) aktarılır, devre ana kartında montajlı bulunan SIM kart (c) aracılığı ile "http" adresine değer yazdırılır. Donanımda ayrıca haberleşme sistemine montajlı bulunan SIM kartın uydu ile bağlantısını güçlendirmek için bir adet anten (d), sistemin güç ihtiyacını karşılamak için iki adet 5000 mAh'lik lityum polimer pil (e) ve haberleşme sistemini dış ortamdan korumak için IP67 koruma sinıfinda montaj kutusu (f) bulunmaktadır.

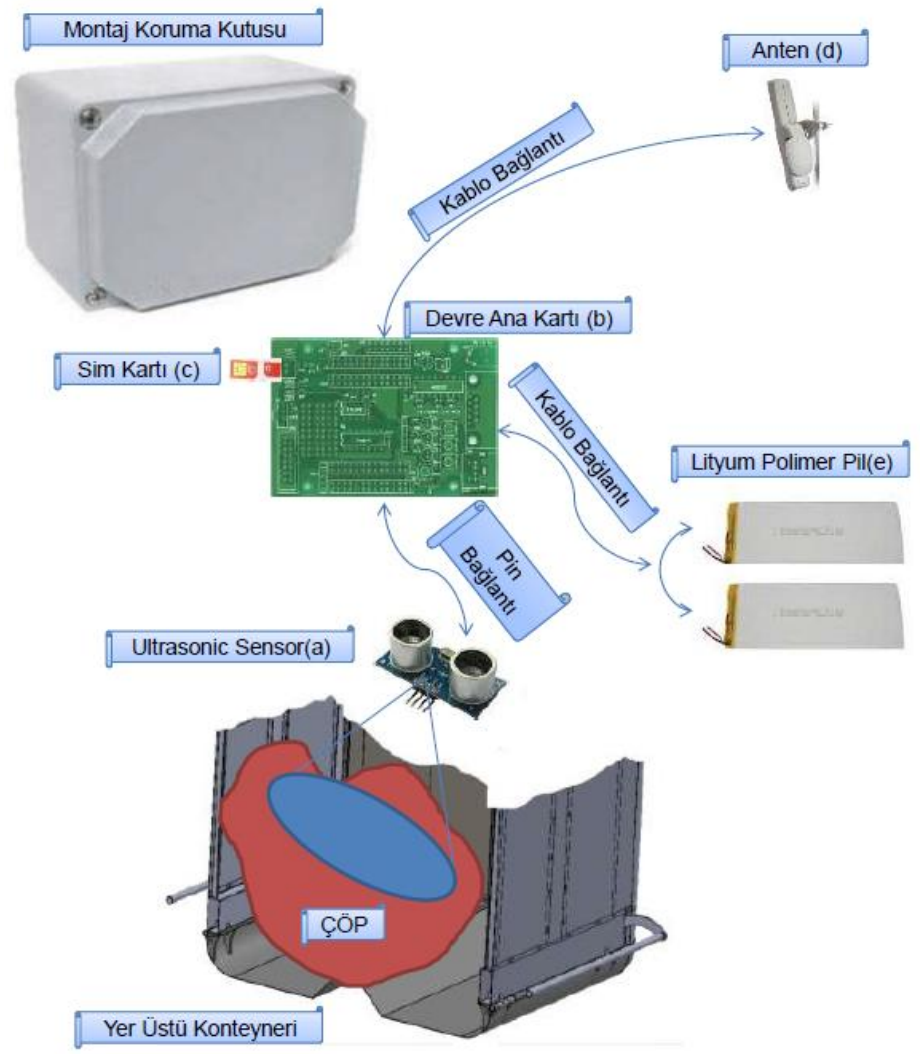

Şekil 6. Akıllı çöp toplama sistemi detayı

Konteynırdaki çöp miktarının aktarılmasından sonra konteynıra dijital kimlik verme işlemi gerçekleştirilmektedir. Bu süreçte çözüm olarak RFID sisteminden faydalanılmış, konteynır üzerine yerleştirilen RFID Tag sayesinde konteynıra belirli bir dijital kimlik verilmiştir (yak000001, yük000001 gibi). Verilen bu dijital kimlik ile hangi konteynırın dolduğu, hangi konteynırın boşaltıldı̆̆ı, hangi konteynırdan kaç kg çöp çıktı̆̆ bilgisini elde etmenin yanı sıra bölgelere göre çöp oranlarının belirlenmesi ve bu bilgi ile bölgedeki konteynır sayısının yeterliliği gibi konularda karar verme amaçlı bir akıllı sistem yapısı kurulmuştur.

\subsection{Araç (Robotik Çöp Toplama Aracı)}

Araç yaklaşık 300 adet farklı standart malzemeden ve 550 adet farklı bileşenden oluşmaktadır. Robotik çöp toplama aracının ağırlığı yaklaşık olarak 17 ton'dur. Sistem başlangıç hareketini araçtan alır. Araca ara şanzıman ile bağlanan iki adet hidrolik dişli pompa şanzımandan aldığı kinetik enerjiyi hidrostatik enerjiye çevirerek hidrolik eyleyicilerle sistemin çalışmasını sağlar. Sistemin hareket kontrolü için bir otomasyon sistemi tasarlanmıştır. Hidrolik valflerin (oransal, selanoid) otomasyon sistem yazılımı ile bütünleşik çalışması sonucu istenilen hareketler \%0,1 hassasiyetle gerçekleştirilebilmektedir. 
Sistemin çalışma detayı da şu şekildedir: Sürücü çöp konteynırını almak için manevra yaptığında, kokpite monte edilmiş 10" ekrandan yatay bomdaki kameralar aracılığı ile konteynır hizalanır, aracı vitesten çıkarmak için debriyaja basılır ve vites boşa alındıktan sonra el fireni çekilir. Debriyaja tekrar basılarak 1 numaralı butona basılır (Şekil 7), PTO devreye girer ve pompalardan sisteme yağ aktarılır. Joystick üzerinde 2 no'lu butona basılır ve joystick tutuş pozisyonuna göre ileriye doğru sürülür, sistem otomatik pilotta harekete başlar, aynı zamanda aracın sağ ve sol yanlarındaki denge ayaklarıyla kasa üst çöp boşaltma kapağı açılır. Yatay bomlar ileriye doğru hareket eder, tutucu kafa kavrama ağzı, yatay bomlardaki lazer mesafe algılayıcılarından gelen bilginin enkoder ve açı algılayıcılar tarafından okunması ile konteynır kavrama bölgesine en yakın mesafeye kadar yol alır. Konteynır kavrama noktasının rahatlıkla yakalanması için joystickteki 2 no'lu düğmeye basılarak tutucu kafanın sağa-sola, 2 no'lu ve 3 no'lu butona basılarak ileri-geri hareketi ile kavrama işlemi daha da kolaylaştırılmış olur. Kavrama işlemi ile birlikte kafaya monte edilmiş RFID anten konteynır üzerinde bulunan RFID tag'a RFID writter ile yazılmış numaraları dikey ve yatay radyo frekansları ile okur, bu numaralar konteynırın dijital kimliğini ifade eder. Okunan değerler daha sonra portala gönderilmek üzere PLC'ye kaydedilir. Kavrama işlemi tamamlandıktan sonra joystickteki 2 no'lu butona basılır ve sistem hareketine devam eder.

Konteynır askıya alındığında dikey boma giden hidrolik hat üzerine yerleştirilmiș transmitter ile konteynırın ağırlık bilgisi elde edilir ve daha önce RFID tag’tan okunmuş konteynır kimlik bilgisi ile eşleştirilir. Böylece hangi konteynırdan kaç kilo çöp alındığı bilgisi belirlenmiş olur. Belirlenen bilgiler, PLC sistemine entegre edilmiş modem router (3G internet) aracılığıyla http adresine API olarak gönderilir. Konteynır kasa üst çöp boşaltma bölgesine geldiğinde tutucu kafadaki pim basma mekanizması devreye girerek konteynır alt kapakların açılmasını sağlar ve böylece konteynır içindeki çöpler kasaya dökülmüş olur. Ardından kasada bulunan hidrolik sıkıştırma mekanizması ile de çöpler sıkıştırılır.

Çöp boşaltma işlemi bittikten sonra sistem otomatik pilotta konteynırı aldığı ilk pozisyona bırakıp park pozisyonuna geçer. Sistem park pozisyonuna geldikten sonra debriyaja basılır ve PTO devre dışı bırakılır, araç hareket etmeye hazır hale gelir. Robotik çöp toplama aracının kat ettiği yol bilgisi, konum bilgisi, hız bilgisi, boşta çalışma süresi gibi bilgiler bir yazılım ile sağlanmaktadır. Sağlanan bu bilgiler paket yazılımın içerisine yerleştirilmiş SIM kart (M2M) ile ana bilgisayara mesaj gönderilerek yazdırılır.

Robotik çöp toplama aracı kokpitinde (Şekil 7) bir adet PC tablet bulunmaktadır. Sürücü bu tablet ile internete bağlanarak izleyeceği rotayı ve verilen görevleri kolaylıkla görebilir. Ayrıca portala (kullanıcı ara yüzü) bağlanarak gerçek zamanlı konteynır, yol v.b. bilgileri alabilir.

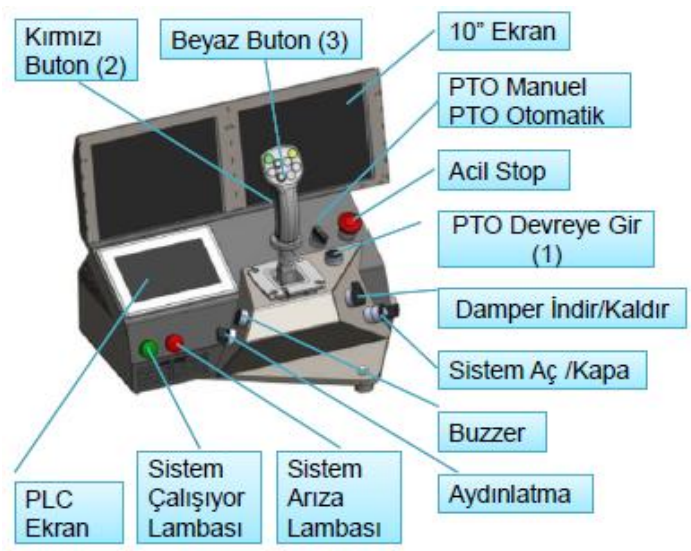

Şekil 7. Çöp toplama aracı kokpiti

\subsection{Portal (Kullanıcı Ara Yüzü)}

Sistemi oluşturan üçüncü grup ise kullanıcı ara yüzüdür (Şekil 8). Bu ara yüz ile sistem ve kullanıcı arasında anlık bilgi paylaşımı, geçmişe dönük raporlar, görev tanımlamaları, çeşitli kıyaslamalar, verimlilik değerlendirme, araç rotalama gibi belli başıı konularda bilgi aktarımı sağlanmaktadır. Portala bilgiler uydu aracılığıyla ulaşmaktadır. Konteynırlarda ve araçta bulunan SIM kartlar (M2M), algılayıcılardan aldıkları 
bilgileri internet ortamına mesaj ile aktarır. Aktarılan bilgiler özel bir yazılım sayesinde istenilen değerlerle kıyaslanarak veya yalın halleriyle kullanıcıya sunulur.

Yazılımın çalışma mantığı şu şekildedir:

- Sisteme portal yöneticisi tarafından ilgili belediyenin sistemsel ihtiyaç tanımlamaları (firma bilgileri, firma ekran lisansları, çalışanları, kullanıcı yetkileri, kullanıcıları) yapılır.

- Sistem sahibi firma tarafindan atık toplamada kullanılacak ürünler ve konum bilgileri (araçlar, kalkış varış noktaları, konteynırlar) tanımlanır.

a) Araç tanımı yapılmadan önce, araç takip modülü araca yerleştirilir.

b) Araç kalkış ve varış noktaları belirlenir.

c) Konteynır sisteme tanımlanmadan önce koordinatları belirlenmiş ve üzerine doluluk algılayıcı ile RFID etiketi takılmış olmalıdır.

- Araçların ve konteynırların içerisine yerleştirilen özel tasarlanmış donanım ve yazılımlar aracılığıyla toplanan bilgiler, düzenli aralıklarda web servis üzerinden sunuculara iletilir.

a) Araca ait modül düzenli aralıklarla aracın konum, hız, km sayaç vb. bilgilerini sisteme gönderir.

b) Konteynıra ait modül düzenli aralıklarla doluluk oranını sisteme gönderir.

c) Araç konteynır tartım modülü konteynırı boşalttığı anda toplanan çöp ağırlığını sisteme gönderir.

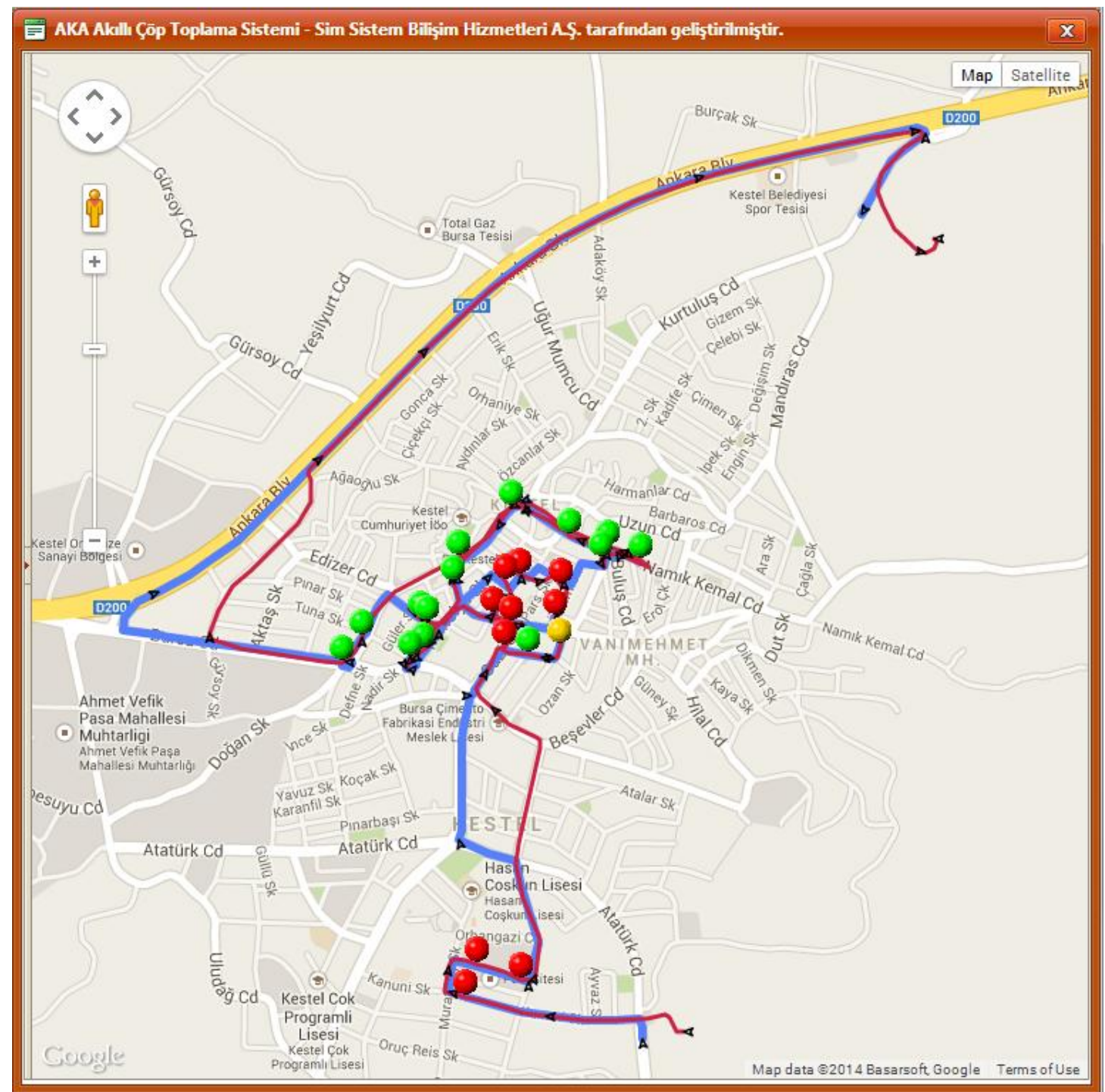

Şekil 8. Portal 
Kullanıcı, yapılan tanımlamalardan sonra araçları ve konteynırları istenilen zaman aralıklarında güncel bilgiler ile izleyebilir ve iş emirleri oluşturabilir.

a) Kullanıcı (yönetici), toplanacak konteynırları ilgili ekran üzerinden planlar ve bu planı sistem sürücüye SMS ile bildirir.

b) Sürücü ilgili iş emrine fiili olarak başlarken portaldan iş emrini başlatır.

c) İş emri başladığı anda araca ait bilgiler izleme ekranından tanımlı süre aralıklarında izlenebilir.

d) Sürücü iş emrini fiili olarak tamamladığında portaldan iş emrini bitirir.

e) Kullanıcı (yönetici), tamamlanan iş emirlerini raporlayıp analizlerini yapabilir.

\section{SONUÇ}

Gelişmiş dünya standartlarında katı atık toplama sistemleri hem geri dönüşüm hem de hijyen (sağlık) açısından çok önem kazanmıştır. Bu tür sistemlerin en az harcama ile en sağlıklı şekilde ortaya konmaları yerel yönetimlerin sorumluluğundadır. Ancak uygulamalar incelendiğinde gelişmiş ülke şehirlerinde dahi çöp toplama işleminin sağlıksız koşullarda ve düşük verimlilikle yapıldığı, bu alanda akıllı sistem çözümlerine ihtiyaç duyulduğu tespit edilmiştir.

$\mathrm{Bu}$ yayında açıklanan yaklaşımlar ve ortaya konan akıllı çöp toplama sistemi, verimli şekilde en az harcama-en az çevreye zarar yaklaşımıyla daha sağlıklı, hijyenik, şehir mobilyasına uygun çözümleriyle, gelişmiş dünyanın sorunlarına çözüm oluşturabilecek teknolojik bir sistemdir. Günümüzün teknolojik imkânları, haberleşme teknolojileri, bu alanda yıllara dayanan tecrübe ve katı atık toplama bilgileriyle birleştirilerek sistem ortaya konmuştur.

Sistemin denemeleri 50000 nüfuslu bir ilçede başarıyla gerçekleştirilmiş ve sistem elemanlarının yanısıra proje çerçevesinde ortaya konmuş olan çöp toplama algoritması da optimize edilmiştir. Kurgulanan yaklaşım esnek bir yaklaşım olup daha büyük şehirlerde de uygulanması mümkündür.

\section{TEŞEKKÜR}

Bu çalışma,1501-TÜBİTAK Sanayi Ar-Ge Projeleri Destekleme Programı kapsamında 3130224 kodu ile desteklenmiş̧tir.

\section{KAYNAKLAR}

[1] VICENTINI, F., GIUSTI, A., ROVETTA, A., FAN, X., HEB, Q., ZHU, M. and LIU, B., “Sensorized waste collection container for content estimation and collection optimization", Waste Management, 29, 1467-1472, 2009.

[2] BONOMO, F., DURÁN, G., LARUMBE, F. and MARENCO, J., "A method for optimizing waste collection using mathematical programming: a Buenos Aires case study", http://wmr.sagepub.com/content/30/3/311.

[3] ISMAIL, Z. and LOH, S.L., "Ant Colony Optimization for Solving Solid Waste Collection Scheduling Problems", Journal of Mathematics and Statistics, 5 (3), 199-205, 2009.

[4] KARADIMAS, N.V., PAPATZELOU, K. and LOUMOS, V.G., "Optimal solid waste collection routes identified by the ant colony system algorithm", Waste Manage Res., 25, 139-147, 2007.

[5] JOHANSSON, O.M., "The effect of dynamic scheduling and routing in a solid waste management system", Waste Management, 26, 875-885, 2006.

[6] FACCIO, M., PERSONA, A. and ZANIN, G., "Waste collection multi objective model with real time traceability data, Waste Management", 31, 2391-2405, 2011.

[7] VIOTTI, P., POLETTINI, A., POMI, R. and INNOCENTI, C., "Genetic algorithms as a promising tool for optimisation of the MSW collection routes", Waste Manage. Res., 21, 292-298, 2033.

[8] NUORTIO, T., KYTOJOKI, J., NISKA, H. and BRAYSY, O., "Improved route planning and scheduling of waste collection and transport”, Expert Systems with Applications, 30, 223-232, 2006.

[9] AREBEY, M., HANNAN, M.A., BASRI, H., BEGUM, R.A. and ABDULLAH, H., "RFID and Integrated Technologies for Solid Waste Bin Monitoring System", Proceedings of the World Congress on Engineering 2010, Vol I, WCE 2010, June 30 - July 2, London, U.K, 2010.

[10] KOP, Y., Fuzzy Multi-Criteria Decision Making in Solid Waste Collection System in Turkey, MSc Thesis, Galatasaray University, 2007.

[11] http://www.ebelediye.info/?pid=22721; Ziyaret Tarihi: 28.01.2014). 